\title{
La arquitectura de las novelas de Agustín Yáñez
}

Las bases arquitectónicas de las novelas de Yáñez son (1) ila predilección del autor por el personaje inolvidable y (2) una tendencia a concebir la obra en dos partes, la segunda de las cuales es una intensificación y exteriorización de la primera. La segunda parte nos revela una circunstancia más amplia, que exige una acomodación de parte del individuo. De esta manera las dos bases de la arquitectura funcionan paralelamente y luego se juntan en el proceso creativo de la obra. Se debe notar que Yáñez maneja muy hábilmente una gran variedad dej técnicas y temas, y que todos contribuyen a la construcción de una o de varias de sus obras. Observaremos en detalle algunos de estos elementos para ver cómo amplían la vida de la obra. Al mismo tiempo, un análisis de la organización de la materia novelesca revelará que los dos factores ya citados son los que dan vida a la obra total.

Agustín Yáñez es un novelista muy humano e igualmente humanista. Se revela sensible frente a las intimas cualidades del hombre, desde Flor de juegos antiguos hasta el complejo de reliquia-tecnología (el papel espiritual que desempeña la máquina de coser) en Las tierras flacas. Busca las cualidades distintivas de cada individuo. Si hay hombres mediocres en las novelas de Yáñez, él los esconde en la multitud de voces anónimas que forman los coros ambientales. Observando el mismo fenómeno desde otro punto de vista, pudiéramos deducir que la mediocridad se encuentra solamente en la masa, no en el individuo.

Refiriéndose específicamente a $A l$ filo del agua, Carmen Andrade observa que "la estructura de la novela está realizada en dos planos: uno el de los personajes que llevan todo el peso de la trama, y el otro que, a modo de fondo musical, forman los coros que éncierran las voces del pueblo en $\tan$ diversos matices..."'1 Es algo desconcertante la ex-

1 "Al filo del agua, novela clásica de Agustín Yáñez", supl. de El Nacional, 5* época, núm. 28 (6 oct., 1968), p. 1. 
presión "en dos planos" porque sugiere que ambos elementos no se entrecruzan. Dejando a un lado esta ligera duda, surgida probablemente de la dificultad de encontrar la palabra que comunique exactamente lo que se observa, confirmamos que hay una distinción fundamental entre los personajes individualizados y el coro anónimo. Este es ambiental. A veces sí desarrolla la trama, como en el episodio de los músicos, revelando un estado anímico general que sirve para iniciar o promover la acción de una o varias de las personias identificadas. Yáñez emplea esta técnica no solamente en Al filo del agua sino en todas sus novelas.

E1 ambiente de un lugar - la circunstancia social, política, geográfica- es la materia temática de Yáñez. Es imprescindible; sin embargo, señalar la doble representación del ambiente novelado. Una es la condición atemporal expresada de manera impersonal (como en el "Acto preparatorio"), la otra es la temporalización del mismo ambiente (como en el primer capítulo de $A l$ filo del agua), expresada mediante los personajes de la novela. Se debe notar que esta segunda representación persiste, algo desequilibrada por el énfasis en las personalidades extraordinarias, hasta que la intensificación-exteriorización temática restaure la proporción. En $A l$ filo del agua el ambiente es el hermetismo eclesiástico del pueblo, en La creación es la promoción artística en una sociedad cambiante, en Ojerosa y pintada el efecto nivelador de la vida de la ciudad, en La tierra pródiga el empresario ingenuo frente a la organización social, en Las tierras flacas el conservadorismo del ser humano. Las voces del coro siempre comunican estos ambientes, pero el novelista observa la realidad temporal mediante sus personajes individualizados.

Se ha dicho con sobrada razón que el protagonista de Al filo del agud es la circunstancia. También se ve claramente que el propósito de la novela es la revelación de las pasiones que existen dentro del hermetismo cultural. El autor nos comunica el ambiente mediante su lírico "Acto preparatorio". Este prólogo a la novela describe una realidad atemporal, vigente pero destilada. Yáñez desarrolla la misma realidad ya perfectamente temporal, empleando a sus personajes nombrados. Lo importante para explicar nuestro análisis de la arquitectura es que el novelista, al presentar el ambiente del pueblo en forma de realidad temporal, lo efectúa mediante una serie de individuos en el primer capítulo. El lector aprecia los problemas de cada uno, frente al fondo sostenido por el tema central. Pero éste se hace realidad actual, en la 
mente del lector, por medio de la caracterización. El efecto del coro es renovar la condición atemporal.

Cada uno de los personajes de ese primer capítulo es revelado como persona particularizada e interesante. Las obras de Yáñez siguen presentando caracteres extraordinarios: Gabriel, el huraño creador; Luis Gonzaga Pérez, el místico innovador; Epifanio Trujillo, el patriarcaarriero-refranero; Ricardo Guerra Victoria, el soñador, pico de oro, atrapado entre el individualismo y la burocracia; el chiflado del canal, filósofo o profeta; Lucas Macías, el "registro civil" del pueblo; Matiana, más mito que persona. Pudiéramos nombrar a muchos otros que recordamos por sus cualidades únicas. Opinamos que a Agustín Yáñez, humano y humanista, le atraen las personalidades extraordinarias y que observa la circunstancia a través de ellas.

La realidad que conocemos en las caracterizaciones de Yáñez es muy intima $y$ es muy posible que la circunstancia se subordine, en la reacción del lector, al interés por los personajes inolvidables. Sin embargo, la segunda parte de la concepción binaria de cada novela restaura la proporción necesaria para comunicar una realidad redonda en que la circunstancia y los personajes son de igual importancia. Es notable que Emmanuel Carballo, sin ver la arquitectura exactamente como la vemos nosotros, ha dicho que "Yáñez como novelista padece de agorafobia: todas su obras son circulares, están redondamente concluidas". "La segunda parte siempre toma en cuenta un mundo más amplio que el escenario de la primera parte. En la primera mitad de Al filo del agua, conocemos el hermetismo del pueblo, las pasiones subterráneas y los intrusos (los norteños), pero todos, incluso los norteños, pettenecen al pueblo. En la segunda parte, el mundo es más amplio, los intrusos no pertenecen al pueblo, los norteños ya son revolucionarios. Toda la emoción sentida en la primera parte se vuelve a sentir más intensamente y tomando en cuenta el mundo afuera del pueblo.

De manera semejante con La creación, la obra creativa de Gabriel, en la primera mitad se desarrolla cuando el músico está en la provincia, muy apartado de la vida artística de la capital. Su problema de artista es más bien íntimo. En la segunda parte, el acto creativo se relaciona con las ambiciones, las envidias, las dudas y la política, que etan características del mundo artístico post-revolucionario. En Ojerosa y pintadd, el chofer lo ve todo desde un punto de vista personal, en la primera parte de la novela. Luego, después de su encuentro con el filósofo

2 "Entre libros", Nivel, 2a época, núm. 13 (25 enero, 1964), p. 3. 
del canal, se vuelve contemplativo en un sentido más amplio, tomando en cuenta los nexos entre sus observaciones y la sociedad.

En la primera parte de La tierra pródiga se observa a distancia la influencia de la sociedad exterior, pero el campo de la acción, es fundamentalmente, el mundo medio salvaje de Ricardo Guerra Victoria y las otras "fieras". En la segunda parte, la organización cívica le quita a Guerra Victoria el papel de empresario. El poder de don Epifanio, de limitaciones claramente regionales, domina la primera parte de Las tierras flacds. En la segunda, observamos el ascenso de Jacob Gallo, igualmente personalista pero quien trae a la región los artefactos del progreso tecnológico. En las cinco novelas, la intensificación y exteriorización del tema y de las emociones en la segunda mitad, funciona algo así como la repetición de un tema musical. Es una reiteración; pero es más, porque proporciona la satisfacción de la redondez.

El mismo autor reconoce la arquitectura binaria de Al filo del agza. Explicándole a Carballo la génesis de esta novela, le informa que el octavo capítulo, "Canicas", corresponde a la incertidumbre que tenía el autor: "Mi situación era, en ese momento, parecida al instante en que las canicas se detienen, en las guías de clavos de los juegos de feria, y no se sabe por cuál lado han de ir". ${ }^{3}$ Efectivamente, "Canicas" funciona más como intermedio que como capítulo en el desarrollo de la novela. Esta obra consta de un prólogo que es el conocidísimo "Acto preparatorio". y dieciséis capítulos numerados. Solamente catorce contribuyen orgánicamente al desarrollo de la novela.

En "Canicas" el autor toma en cuenta el enredo de personajes y circunstancias, observa la falta de resolución y mira hacia el porvenir. El capítulo siguiente, el noveno, debe considerarse una obertura a la segunda parte de la novela. Corresponde al "Acto preparatorio". No es exactamente igual que el mencionado prólogo porque ya estamos metidos dentro de la novela. La experiencia de la obra ya incluye a varias personas identificadas y no sería interesante progresar sin ellas. El "Acto preparatorio" es completamente ambiental - de una innegable realidad pero sin referencia a ningún personaje específico. ${ }^{4}$ Parece perfectamente natural al principio de la novela. Por el contrario, sería artificioso intercalar en medio de la obra un capítulo que no mencionara a los per-

3 Emmanuel Carballo, Agustin Yáñez (Habana: Casa de Las Américas, 1966), p. 16. También se aprecia la situación del autor frente al problema de la novela, dentro de la obra. Véase $A l$ filo del aguza (México: Potrúa, 1955), p. 164-165.

${ }^{4} \mathrm{El}$ autor nos informa que cuando escribió el "Acto preparatorio" no había pensado en Al filo del agua. Véase Carballo, Agústin Yánez, p. 15. 
sonajes. Sin embargo, este noveno capítulo, "Victoria y Gabriel", tiene mucho en común con el "Acto preparatorio". En lo que se refiere al estilo, notamos en ciertos pasajes la supresión de formas verbales variables y las repeticiones que engendran el efecto incantatorio (de canto ritual) que el autor emplea frecuentemente en sus pasajes ambientales. El Gabriel que encontramos a principios del capítulo es más símbolo que personaje de carne y hueso. A este Gabriel, "nuncio y péndulo", el novelista lo relaciona con el leitmotiv del "Acto preparatorio", "pueblo de mujeres enlutadas". " Más tarde el responso de Victoria al arte de Gabriel establece un nuevo leitmotiv mediante la repetición de "a través de la muerte" (183-184). Estas técnicas producen el tono elevado de este capítulo que varios críticos consideran exagerado o melodramático. "No lo es más que el "Acto preparatorio", aunque es posible que adolezca de un choque entre el tono elevado y el sentido de vida cotidiana causado por la identificación específica de los personajes. Esta inconsistencia es mínima si efectivamente leemos el capítulo como la obertura a la segunda parte, no como un paso más en el desarrollo de la primera.

Debemos aclarar que no estamos hablando de los planes ni las intenciones del autor sino de la arquitectura (organización) de la novela que el lector aprecia, aunque subconscientemente. Con frecuencia el lector descubre detalles de esta arquitectura que enriquecen la experiencia de leer la novela. Si aceptamos las funciones especiales de "Canicas" y de "Gabriel y Victoria", la novela adquiere una simetría que aumenta el efecto armónico siempre deseado por Yáñez. Asi vemos que la obra consta de (1) la obertura a la primera parte ("Acto preparatorio"), (2) siete capítulos que son el tema de la obra, (3) el intermedio ("Canicas"), (4) la obertura a la segunda parte ("Gabriel y Victoria") y (5) siete capitulos que producen la intensificación y exteriorización de la primera parte.

Gabriel desempeña el máximo papel en la expansión del tema que apreciamos leyendo los siete capítulos de la segunda parte. Participa el campanero en la prefiguración de la Revolución que se presenta en "Ca-

5 Al filo del agua (México: Porrúa, 1955), p. 178. En adelante nos referimos a esta edición, citando los núms. de las págs. en el texto del ensayo.

- Elaine Haddad revela las muchas variaciones de la opinión crítica en su artículo, "The Structure of $A l$ filo del agua", Hispania, XLVII, (Sept., 1964), pp. 525-526. La autora comprende que "Gabriel y Victoria" es un intervalo (lo llama "interlude" en p. 525 de su artículo), pero aparentemente no considera que este atributo le confiera valores especiales, puesto que opina que es melodramático. 
nicas". No parece muy significativo que aparezca por primera vez en este capítulo. A pesar de ser familiar del párroco, no lo menciona Yáñez en el tercer capítulo ("Marta y María"), que está dedicado a la casa del padre Dionisio. El novelista lo introduce cuando quiere ampliar el sentido de cambio profundo e inmanente; gracias al arte de Gabriel, este cambio no será solamente político sino también creativo. El procedimiento titubeante de este intermedio eslabona tres elementos esenciales a la prefiguración. Uno es Gabriel, artista y por eso iniciador de cambio. Segundo, Victoria, que es, como la Revolución, una in. fluencia perturbadora llegada del exterior y al mismo tiempo es la mujer clásica que responde al arte-creación de Gabriel. El tercer elemento es la inferencia con que termina el capitulo. Comparando a los personajes con las canicas de los juegos de feria, el autor concluye que "Va rodando la bola" (176), que se refiere igualmente al personaje-canica y a la acción revolucionaria. En el capítulo noveno, que señalamos como la obertura de la segunda parte, se refuerza la función de la creación artística en los capítulos que siguen, cuando la Revolución llega a ser la expresión más intensificada de las emociones subterráneas de la primera parte. Mediante el arte, Victoria comunica la extroversión de los valores creativos y Gabriel quisiera hablar de esos mismos valores y su relación con el pueblo a que pertenece el artista (180-184). Cambio y estabilidad.

La explicación de la intensificación temática de $A l$ filo del agua no se basa en un paralelismo cronológico sino en una repetición de tensiones y de afinidades. Joseph Sommers ha explicado con maestría cómo funciona el concepto de tiempo en esta novela. ${ }^{7}$ Observa que varias líneas de la trama progresan al mismo tiempo, cada una con su ritmo único y natural, y que el lector tiene que reordenar las secuencias. Diríamos a Sommers que solamente esto sería necesario si el lector exigiera el orden cronológico. El procedimiento de Yáñez es más eficaz que el orden cronológico para revelar las personalidades y las tensiones que emanan de ellas. Sin preocuparnos por la cronología apreciamos la intensificación temática.

En el primer capítulo, Yáñez revela la circunstancia mediante la angustia de cuatro personajes muy distintos entre sí. El lector reconoce que ni la posición acreditada en el pueblo, ni la tragedia familiar, ni el

7 After the Stom: Landmarks in the Modern Mexican Novel (Albuquerque: University of New Mexico Press, 1968), pp. 47-49. 
amor, ni la rebelión rescatan a estas personas del ambiente opresivo. Todos los episodios nos advierten que una rebelión es posible, pero la condición en cada caso es completamente íntima. En el primer capítulo de la segunda parte ("El Día de Santa Cruz") es todo lo contrario. Micaela, que en su primer episodio regresa de la ciudad sin ganas de rendirse otra vez al hermetismo del pueblo, en la segunda parte recibe a Damián por primera vez. Sobra decir que la emoción es más intensa. Se debe notar también que Damián simboliza el mundo exterior y que para Micaela él es más importante como enfoque de su rebelión que como un posible amante. En el mismo capítulo, el autor nos revela la pesadilla del cura, Don Dionisio, en lugar de la de Don Timoteo, con la que comienza el primer capítulo. La diferencia está en que ésta se refería solamente al sentido de culpa de Don Timoteo; pero la del cura toma en cuenta todo el pueblo y el papel que desempeña la religión entre sus feligreses. Una tendencia exteriorizante adicional se aprecia en el tercer encuentro de Gabriel con Victoria.

Inmediatamente después de comunicar el ambiente opresivo en la primera parte de la obra, el autor revela el centro de la opresión en un capítulo dedicado a los clérigos y los ejercicios religiosos. En un episodio correspondiente de la segunda parte, la represión eclesiástica se intensifica cuando el Padre Islas no quiere oír la petición de Damián referente a Micaela. Todor el capítulo dedicado al Padre Islas ("El Padre Director") obra con la pesadilla de Don Dionisio, en el capítulo antecedente, para indicar que la represión no es solamente el producto de la religión, sino de un complejo de influencias del que los clérigos también son víctimas.

Es notable la distorsión de la cronología que se observa entre este capítulo y el siguiente, porque revela la importancia del personaje extraordinario en la arquitectura de la novela. Al final de la infructuosa entrevista que ensaya Damián con el Padre Islas, el novelista nos informa que "esto fue a fines de junio" (236). La acción del capítulo siguiente, "Ascensión", toma lugar anteriormente, pero el capítulo no es un flasbback sino otra línea de la trama. La función del episodio Damián-Padre Islas es lograr la caracterización del cura inflexible. El personaje es más importante que la cronología.

Siguiendo la observación de la intensificación temática, encontramos una diferencia fundamental en dos descripciones de la vida familiar de Don Dionisio. En la primera, ("Marta y María"), conocemos las personalidades de las dos muchachas y sobre todo los anhelos y las pe- 
queñas desobediencias de María. Pero esto ocurre en una casa contenta, muy controlada. En "Ascensión", la vida de la casa es desajustada: Gabriel decide que tendrá que alejarse del pueblo, María está completamente enajenada.

La religiosidad de Luis Gonzaga Pérez se intensifica y se exterioriza cuando Micaela no llega a ser una de las Hijas de María. En cierto sentido estos episodios versan sobre la intrusión eclesiástica en la vida laica. La tragedia de Luis Gonzaga es íntima, o familiar -en el pueblo es materia de chisme. Lo que le pasa a Micaela, al contrario, termina con la tragedia de Damián Limón, acontecimiento que hace temblar los fundamentos del orden establecido.

El cambio ya es definitivo. El cronista del pueblo, Lucas Macias, siempre fue una especie de conciencia del pueblo en lo que se refiere al mundo exterior. En la segunda parte menciona con más frecuencia el nombre de Francisco I. Madero, intensificando el significado al repetir, más o menos, las mismas palabras en forma de estribillo. Los norteños, en el último capítulo de la primera parte, al traer nuevas ideas, alteran la vida del pueblo. En el último capítulo de la segunda parte, son los revolucionarios. Una intensificación igual se observa en el factor supersticioso del ser humano. La güija que atrae Bartolo en la primera parte prefigura el cometa de Halley en la segunda. La exposición de las injusticias sociales dirigida al "padrecito" en "Los norteños" (152153) culmina en las divagaciones de Don Dionisio al final de la novela, cuando se pregunta si la Revolución pudiera ser un instrumento de la Providencia (386).

Al terminar la última página de Al filo del agua, el lector se da cuenta de que Don Dionisio es más protagonista de lo que parecía a principios de la obra. Poco a poco se aprecia que él se siente responsable por todos, personalmente y además como sacerdote. Hasta cierto punto es el símbolo de la religión (no de la iglesia que es mucho más complicada) y en los últimos momentos de la novela lo vemos como símbolo y al mismo tiempo como un ser humano inolvidable.

Se debe aclarar que la construcción de la novela a basel de personajes extraordinarios no es lo mismo que el procedimiento realista de escribir una semblanza del personaje antes de entrar en la acción de la novela. Yáñez revela la circunstancia, la acción o el problema desde el punto de vista del personaje, empleando frecuentemente el monólogo interior. La intensidad -o digamos la hondura- de la interiorización varía según las exigencias del desarrollo de la obra en un momento 
determinado. ${ }^{8}$ Lo que hace con Don Timoteo y los otros personajes del primer capítulo de $A l$ filo del agua es muy semejante al procedimiento que emplea en sus otras novelas, todas con variaciones particulares, desde luego. Por el momento dejamos de lado La creación y Ojerosa y pintadla, que tienen características muy especiales, para ver primero las obra. que se asemejan más a Al filo del agua. Tales son: La tierra pródiga y Las tierras flacas; en ambas se revela con toda claridad la preocupación por las personas definitivamente caracterizadas.

El primer capítulo de La tierra pródiga es una caracterización de las "fieras", los explotadores de la región. Cada uno se revela mediante una alternación de lo que dice abiertamente y lo que piensa interiormente (en letra cursiva). Apreciamos la riqueza de la comarca y los grados de primitivismo de los personajes, al combinar lo que dicen y piensan ellos con la síntesis de la circunstancia hecha por el ingeniero Pascual Medellín. El personaje más extraordinario de todos, Ricardo Guerra Victoria, no entra hasta el segundo capítulo, que es, en casi su totalidad, una caracterización de este empresario. Guerra Victoria es un hombre de gran inteligencia, sin mucha educación formal, medio soñador y medio oportunista, promotor de mucha resonancia en la comarca, pero algo inocente en el gran mundo. La novela sigue desarrollándose según las tensiones entre él y las otras "fieras" de un lado, y del otro lado entre él y la organización cívica. Guerra Victoria es el único verdadero protagonista que encontramos en las obras de Yáñez.

La acción en estos dos capítulos no adelanta la trama de la novela, sino que aclara las caracterizaciones y las circunstancias. Luego el novelista va elaborando el tema hasta fines del quinto capítulo, y lo exterioriza, intensificándolo, en los cuatro capítulos restantes. La primera parte termina con estos datos: "Guadalajara, abril-agosto de $1958^{\prime \prime},{ }^{9}$ y la segunda fue escrita en "San Miguel Chapultepec, abril-agosto de 1960" (315). Efectivamente, la primera parte, con pocos cambios, pudiera ser una novela completa.

Empleando dos planos de tiempo, Yáñez explica los antecedentes de la circunstancia actual. Escribe del pasado sin perder de vista el presente. El quinto capítulo tiene acción rápida, revelando que el protagonista ha sido casi arruinado por sus enemigos y las fuerzas de la natu-

8 Samuel J. O'Neill ha estudiado este fenómeno en "Interior Monologue in Ai filo del agua", Hispania, LI, 3 (Sept.. 1968), pp. 447-456.

${ }_{9}$ La tierra pródiga (México: Fondo de Cultura Económica, 1960), p. 179. En adelante citamos las páginas de esta edición en el texto del ensayo. 
taleza. Se salva por su habilidad para convencer a los demás. La novela pudiera terminar con esta victoria, pero el novelista nos avisa que Sotero Castillo, el más obstinado de los enemigos, no se humilla ante Guerra Victoria. Sotero funciona como transición hacia la segunda parte, igual que Gabriel en $A l$ filo del agua.

En la segunda parte de la novela, la lucha entre los explotadores se especifica. Ahora se trata solamente de la derrota de Sotero por el protagonista. Pero durante este episodio, Guerra Victoria, que siempre ha representado la influencia del mundo de afuera, en la tierra pródiga pierde contacto con los oficiales y descubre, cuando ya es tarde, que el desarrollo de la región será efectuado sin la dominación de él. Su individualismo, que siempre trataba con la organización cívica sin entenderla, es sustituido temáticamente por esta fuerza exterior.

La organización de Las tierras flacas presenta un aspecto visual más interesante que el de La izerra pródiga. Está dividida en cinco "estancias", que llevan los nombres bíblicos de una serie de lugares de la región combinados con unas indicaciones del tema de cada "estancia"; por ejemplo: "Betania: la tierra o la máquina". Se establece cierto ritmo de organización porque cada "estancia" contiene tres subdivisiones (1a quinta contiene cuatro, como una serie de tercetos que terminan en un cuarteto). Cada subdivisión lleva como título las primeras palabras de los textos correspondientes (como se hace con frecuencia en la poesía), y siempre constituyen algún dicho de sabor folklórico. Este plan de novela es el más complicado y armónico que ha hecho Yáñez, con la posible excepción de La creación.

La primera "estancia" de esta novela, como los primeros capítulos de Al filo del agua y La tierra pródiga, establece la circunstancia mediante los personajes inolvidables: Los principales son tres, y cada uno de ellos plantea el tono de la subdivisión que le corresponde. En esta novela el tema es una síntesis de la circunstancia. Epifanio Trujillo, el cacique, codicia la máquina de coser que es el símbolo de su obsesión por la fallecida Teódula. Dada la superreligión de la gente de la comarca, el artefacto representa al mismo tiempo la redención y el poder de don Epifanio. En la primera subdivisión, observamos esta circunstancia a través de Rómulo, padre de Teófila, dueño de la máquina y de unas pobres tierras que hasta el momento don Epifanio no le ha quitado. La perseverancia y honradez de Rómulo parecen casi absurdas en vista de la increíble pobreza de las tierras flacas. Su carácter es igual al del ambiente de la región. En la segunda subdivisión, observamos el caso desde el punto 
de vista de Epifanio, el patriarca refranero ya casi inmovilizado por la obesidad. La caracterización de Matiana, de matices sobrenaturales, domina la última subdivisión de la primera "estancia".

La narración se conforma con el mismo triunvirato de personajes en la segunda "estancia", donde presenciamos el regreso de Jacob Gallo (Miguel Arcángel), el hijo rebelde de Epifanio. La tercera "estancia" produce la transición entre las dos partes de la arquitectura binaria de Las tierras flacas. En la segunda subdivisión de esta "estancia", se observa que la importancia de Epifanio se va disminuyendo a medida que se aumenta la de Jacob Gallo.

La primera parte de la novela ("estancias" I y II) está basada en el poder de Epifanio. En la "estancia" de transición estalla la violencia entre el poder de Trujillo y el de Gallo. En la segunda parte ("estancias" IV y V), Jacob Gallo y sus artefactos del progreso tecnológico reemplazan definitivamente el caciquismo totalmente regional de don Epifanio. Lo que no quiere decir que lo bueno existe en lugar de lo malo, sino que la vida de la comarca será distinta. Una vez establecida esta influencia del exterior, la gente se vuelve más activa, pidiendo justicia, por ejemplo, en casos que antes hubieran evocado una triste resignación.

En esta novela no le hace falta al narrador un personaje-trampolín como Gabriel y Sotero, porque la tercera "estancia" sirve para llevarnos hacia la intensificación del tema. En la subdivisión de la cuarta "estancia", que corresponde a Epifanio, el patriarca se muere. Esto desconcierta momentáneamente al lector, quien ya se ha acostumbrado al ritmo del triunvirato Rómulo-Epifanio-Matiana. La función de Rómulo se ve claramente en la primera subdivisión. La segunda, donde buscamos la intervención de Epifanio, es un ensayo lírico de efecto incantatorio y que anticipa la temporada de lluvias. Al final de la subdivisión, se muere Epifanio, y empiezan las lluvias. De inmediato notamos que es muy acertada esta desaparición gradual del patriarca. En cuanto a la subdivisión que corresponde a Matiana, parece que su acción es mínima, pero hace exactamente lo que es más lógico en su caso: milagrosamente sabe, con precisión, cuando don Epifanio deja de respirar y le avisa a Jacob Gallo.

Nótese que en la segunda subdivisión de la última "estancia" aparece Plácida, la hija neurótica de Epifanio, en lugar de su progenitor, donde por lógica, esperábamos a Jacob Gallo. El efecto que crea Yáñez con este procedimiento es el de recalcar el final de don Epifanio, de manera que el ascenso de Jacob Gallo resalta menos en la mente del lector. La victoria del hijo se observa más en una especie de epílogo, 
que es la cuarta subdivisión de la quinta "estancia". Aun cuando presenciamos la fiesta de las luces (eléctricas) -otra Epifanía- nos quedamos con muchas dudas con respecto a la eficacia de esta clase de progreso en una región donde tanta tensión surge del conflicto entre la realidad visible y la inventada por la gente según sus necesidades emocionales. La función de epílogo justifica plenamente el uso de cuatro subdivisiones en la última "estancia".

El efecto estético logrado mediante el plan detallado de Las tierras flacas es, a nuestro parecer, muy superior a los efectos obtenidos en $L a$ creación, la otra novela cuya organización presenta un aspecto interesante. Esta organización - no el tema- nos parece que es una experiencia de la que después surge Las tierras flacas. Yáñez compone el libro en forma de sinfonía, probablemente porque su personaje principal (Gabriel es demasiado débil para ser protagonista) es músico. Los cuatro "movimientos" son "andante", "creciente", "galopante" y "vehemente". En realidad la novela no se intensifica según estas indicaciones.

El primer "movimiento" es como un epílogo a Al filo del agut, a pesar de lo que indica el autor referente a la autonomía de sus novelas. ${ }^{10}$ Lo que nos llama la atención es la elaboración de varios temas planteados en la novela antecedente: la educación musical de Gabriel, la personalidad de Victoria, la carrera revolucionaria de María. La presentación de la circunstancia en esta novela es distinta de la que emplea Yáñez en las tres novelas de provincia. En el primer capítulo de La creación el manejo de los personajes inolvidables está invertido. Estos son Victoria y Matía, y las vemos mediante los recuerdos de Gabriel. La circunstancia en que vive el joven músico es controlada por el patrocinio de las dos mujeres, y ellas representan dos aspectos de la circunstancia exterior: Victoria es la benéfica burguesía que fomentaba la expresión artística a base de recursos particulares, y María es el nuevo mundo de poder y favores políticos. Ambas mujeres son elementos de los dos polos del conflicto en Gabriel, conflicto del que emana, al mismo tiempo, su sensibilidad y su debilidad. Se debe notar que varios personajes históricos y bastante extraordinarios desempeñan el papel de protagonistas porque la novela pinta un panorama de la actividad artística en la capital después de la etapa bélica de la Revolución.

La diferencia temática entre la primera y la segunda mitad de esta novela es la ampliación de la circunstancia. El primer capítulo ("movimiento") revela el problema íntimo de Gabriel, el segundo está basado

10 Carballo, Agustin Yáñez, p. 18. 
en su productividad en la provincia. En el tercer "movimiento" volvemos a ver la concentración en el problema íntimo, esta vez en términos de la gran cultura (las musas, las gracias, etc., en la pesadilla de Gabriel). El cuarto "movimiento", como el segundo, versa sobre la productividad del músico, ya en el mundo artístico de la capital (nativismo versus cosmopolitismo, veladas panartísticas, etc.). Se observa que el mundo íntimo de Gabriel se abre y él tiene que ubicarse en este mundo más extenso y menos suyo.

Conviene comentar brevemente la función del tercer "movimiento", que es algo preciosista por ser exagerada y falsamente culto. Se debe notar que el segundo movimiento termina con una subdivisión intitulada "El Banquete", que es una velada de artistas. Las últimas palabras de esta parte son anónimas: "Que viva el amor, serenos". ${ }^{11}$ La subdivisión en general y estas palabras específicamente constituyen el agente que nos conduce a la segunda parte. Aquí el novelista no emplea el personaje de transición. La velada es el mundo artístico de la capital, el amor es el de Pandora, que es el medio de identificación que emplea Gabriel. Este se encuentra en un estado de embriaguez, en el tercer "movimiento", y la pesadilla es causada por la ampliación de la circunstancia. Para Gabriel el conflicto se basa en la definición del arte y en la definición de la mujer (Victoria-María). A veces coinciden ambas definiciones. En el primer "movimiento" este conflicto arte-mujer se observa solamente dentro del ser íntimo de Gabriel. El segundo presenta el conflicto en términos de la realidad mexicana, provinciana y luego capitalina. En el tercer "movimiento" observamos el conflicto en términos de la cultura occidental. La apreciación de esta cultura por Gabriel es parcial, y el "movimiento" revela esta deficiencia empleando un tono de vanidad juvenil.

En el cuarto "movimiento" Gabriel encuentra su lugar en el mundo artístico, que es uno de los aspectos de la vida de la ciudad en Ojerosa $y$ pintada. El procedimiento en esta segunda novela de la ciudad también es distinto del de las novelas de provincia. En Ojerosa y pintada no hay caracterizaciones desarrolladas porque se trata del día (veinticuatro horas) de un chofer de taxi y los usuarios cuyos asuntos entrecortan su día más o menoş plácido.

Casi todos los críticos de la obra de Yáñez han observado la influencia de Manbattan Transfer, de John Dos Passos, influencia reconocida por el mismo novelista en el caso de $A l$ filo del agua. ${ }^{12}$ Se observa en la revela-

11 La creación (México: Fondo de Cultura Económica, 1959), p. 171.

12 Carballo. Agustín Yánez, p. 15. 
ción de la circunstancia desde el punto de vista de varios personajes. Esto es lo que hace Yáñez en las tres novelas de provincia, e indirectamente en La creación. Pero los personajes de estas obras siguen apareciendo durante el curso de la novela, mientras que los de Ojerosa y pintada aparecen una sola vez. Cada uno sale definitivamente de esta novela, al final de su episodio (hay dos excepciones que no alteran el caso). Empezando con un nacimiento y terminando con una muerte, Yáñez propone construir una secuencia que se integra en una sola vida mítica, la de la ciudad. Pese a lo que dicen los críticos, opinamos que la novela es interesante y que efectivamente capta mucho del ambiente de una gran ciudad. En cambio, notamos que la integración de los episodios es deficiente porque algunos personajes, aún sin ser desarrollados, son destacados debido a que el autor se interesa mucho en las personalidades inolvidables. Tomando en cuenta los propósitos de la novela, sería conveniente que todos los personajes fueran más o menos iguales en el recuerdo. En realidad, varios persisten y otros se desvanecen.

El muchacho de Peralvillo es uno de los primeros que aparecen en la obra y nunca se nos escapa porque su responsabilidad combina con las ideas del filósofo del canal y la fama del General Robles para completar un concepto del ciudadano idóneo. Estos tres personajes forman la base de la arquitectura de la novela.

El muchacho de Peralvillo pertenece a la primera parte. Lo recordamos porque el chofer lo recuerda como si fuera un amuleto de buena suerte. En esta parte de la novela, "Cuesta arriba", el chofer lo ve todo en términos íntimos, personalistas: considera solamente lo que significa una persona en su vida particular. ${ }^{13}$ EI intermedio, "Parteaguas", introduce al filósofo del canal. Este viejo, de modales raros y anticuados, $y$ de hablar incesante y lleno de aclaraciones excesivas, es nuestro guía hacia la segunda parte. Su largo discurso comenta la variedad y la integridad de la gran urbe, las diferencias y las semejanzas, las muchas posibilidades de la vida - la vida que termina en una síntesis de identidades y de los aspectos del tiempo (120).

El chofer se siente ambivalente en cuanto a las ideas del viejo. AI mismo tiempo le chocan y atraen. Se da cuenta de que diariamente él observa el mismo río humano en su carro. Dice esto específicamente

13 Esta novela, como La tierra pródiga, lleva dos fechas de composición. Al final de la primera parte: "San Gabriel de Guadalajara, julio de 1956". Al final del libro: "San Miguel Chapultepec, 11 de agosto de 1959". Ojerosa y pintada (México: Libro-Mex, 1960), pp. 109, 218. En adelante citamos por esta edición. 
en la segunda parte de la novela (138-139). Esta parte - "Cuesta abajo" - termina con la muerte del General Robles. El chofer es menos personalista que en la primera parte. Parece que ya ve los asuntos de sus clientes en términos de una totalidad social y no sólo con referencias a él

El General Robles es un viejo revolucionario de honradez tan intachable como la responsabilidad del muchacho de Peralvillo. Además de sus cualidades morales, tiene un aspecto físico extraordinario, como todos los personajes memorables de Yáñez (213). Esta combinación de cuitlidades es, en cierto sentido, una explicación de la arquitectura de estas novelas. Al novelista le interesa el individuo excepcional y quisiera preservar la identidad única de cada uno. Pero también revela su fuerte sentido de obligación cívica. La exteriorización que se consigue en la segunda parte de la arquitectura binaria, indica la imposibilidad del individualismo independiente. Cada una de las cinco novelas fomenta una reconciliación del individuo con la ampliación de su concepto del mundo o la caída del individuo. Esta clase de progreso es imprescindible. El dolor que exige la reconciliación es expresado por la intensificación temática de la segunda parte. Es por eso que las dos bases de la arquitectura citadas a principios de este análisis, son absolutamente esenciales. Si el autor cultivara a los personajes inolvidables sin intensificar y exteriorizar la primera parte de la novela en la segunda, se quedaría con uns serie de semblanzas y algún ambiente. Si ampliara el tema sin el desarrollo de personas extraordinarias, tendría poco más que un documento social. Empleando ambas bases, produce una obra que da el gusto y envergadura de las construcciones firmes.

JOHN S. BRUSHWOOD

The University of Kansas 
